\title{
Nonsurgical Rejuvenation of the Eyelids with Hyaluronic Acid Gel Injections
}

\author{
Seongmu Lee, $\mathrm{MD}^{1} \quad$ Michael T. Yen, $\mathrm{MD}^{2}$ \\ ${ }^{1}$ Department of Ophthalmology, The Southeast Permanente Medical \\ Group, Atlanta, Georgia \\ 2 Department of Ophthalmology, Cullen Eye Institute, Baylor College \\ of Medicine, Houston, Texas
}

Address for correspondence Michael T. Yen, MD, Department of Ophthalmology, Cullen Eye Institute, Baylor College of Medicine, 1977 Butler Blvd, Houston, TX 77030 (e-mail: myen@bcm.edu).

Semin Plast Surg 2017;31:17-21.

\begin{abstract} Keywords

- lower eyelid

- tear trough

- periorbital fillers

- fat prolapse

- rejuvenation

- hyaluronic acid gel

There has been an increased recognition for the role volume deflation plays in the aging periorbital area, and as such, rejuvenation strategies to augment and restore volume have developed and evolved. Hyaluronic acid fillers provide an efficient option for volume augmentation with good efficacy, longevity, and safety. An understanding of the changes in the upper and lower periocular area due to aging, the meticulous identification of focal hollows, and the precise delivery of filler to these areas can smooth contours and restore a rejuvenated periorbital area.
\end{abstract}

Traditional approaches to rejuvenation of the eyelids have typically involved subtractive surgical procedures that remove tissue and fat (and volume) from the eyelids, leading to a hollowed appearance. These invasive procedures can include skin- and muscle-excision blepharoplasty, fat excision and contouring, and eyelid shortening and tightening. However, as our understanding of the components of the aging face has evolved to include an increased appreciation for volume deflation in addition to skin changes and gravitational descent, rejuvenation strategies have also developed and evolved to address the needs of volume restoration.

With the advent of readily available, effective, and lessinvasive treatment modalities, approaches have shifted from traditional subtractive surgical procedures to a more customized, complementary approach of surgical and nonsurgical treatments including neurotoxins, injectable fillers, and skin rejuvenation procedures such as chemical peels and laser resurfacing. A good understanding of the changes in the face due to aging and of the capabilities of these various approaches, meticulous patient selection, and precise delivery of filler can effectively smooth contours and rejuvenate the periorbital area.

\section{Anatomical Changes with Age}

Aging of the face is a complex and dynamic process, with tissue descent, deflation, and external skin changes that can vary from patient to patient. In the youthful face, the periocular area consists of well-toned, elastic skin absent sun damage, a full, well-defined brow without descent, a crisp and visible upper eyelid crease with minimal dermatochalasis, and a taut, well-positioned lower eyelid with minimal laxity or excess skin.

With aging, patients may experience loss of volume, with deflation and hollowing of the upper eyelid, thereby exposing the superior orbital rim. This can result in an appearance of a sunken, hollowed eye, with a deep superior sulcus. There may also be drooping of the brow and dermatochalasis, obscuring the pretarsal platform and the eyelid crease. ${ }^{1-5}$

In the lower eyelids, weakening of the orbital septum and pseudoherniation of the lower lid fat pads can result in the appearance of dark circles and eyelid bags. This can be further exacerbated by decent of the midface/suborbicularis oculi fat and malar fat pads, thereby baring the inferior orbital rim (-Fig. 1). In the areas of attachment of the skin to deeper structures, focal loss of volume along the orbital rim may
Issue Theme Oculofacial Plastic and Reconstructive Surgery; Guest Editor: Douglas P. Marx, MD
Copyright @ 2017 by Thieme Medical Publishers, Inc., 333 Seventh Avenue, New York, NY 10001, USA. Tel: +1(212) 584-4662.
DOI http://dx.doi.org/ 10.1055/s-0037-1598189. ISSN 1535-2188. 


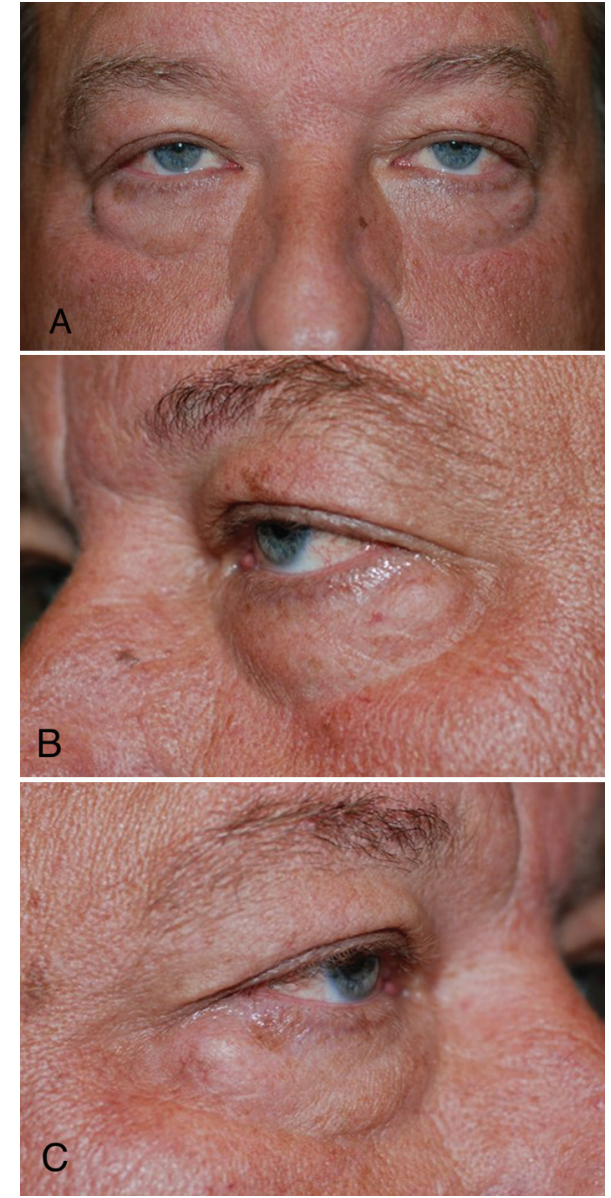

Fig. 1 Images of a patient: both eyes (A), left eye and (B), right eye (C) with pseudoherniation of the lower eyelid fat pads, midface deflation, and descent of the suborbicularis oculi fat and malar fat pads, leading to increased exposure of the orbital rim.

unveil deeper facial contours and mimic the decent of soft tissue. Receding of the superior and inferior orbital rim may further exacerbate volume deflation and brow ptosis. ${ }^{3-6}$

The most common deformity that develops due to these changes is a relative depression near the medial orbit in the area of the lower eyelid-midface transition. There is shadowing in the location of the orbitomalar ligament, otherwise known as a tear trough deformity. Others may develop an additional surface depression in the area of the confluence of the lower eyelid retractors, orbital septum, and tarsal plate, known as the septal confluence. The malar ligament, which limits the suborbicularis oculi fat, also contributes to a focal area of depression in the midface. ${ }^{7-9}$

The recognition of volume depletion in the periorbital area is important, because removing fat and tissue can cause more hollowness and result in the loss of eyelid support, particularly in the area of the inferior orbital rim. Traditional surgical approaches that seek to lift and excise can further bare a deep superior sulcus, accentuating the superior orbital rim. A customized approach seeking to deliver filler with precision to focal hollows in selected patients can be performed to soften surface depressions and mask exposed deeper structures such as the orbital rim ( $\mathbf{F i g . ~ 2}$ ). ${ }^{1,2,6,10}$

\section{Injectable Fillers}

Prior to the availability of synthetic hyaluronic acid fillers, options for volume replacement have traditionally been more limited: autogenous grafting such as fat that requires harvesting, solid implant placement, and fillers such as collagen and silicone. The arrival of newer fillers with an acceptable safety, tolerability, and efficacy profile has provided a useful and practical solution to effectively address volume loss. ${ }^{11-15}$

Hyaluronic acid is a glycosaminoglycan disaccharide consisting of alternating units of D-glucouronic acid and $\mathrm{N}$ acetyl-D-glucosamine. Its structure is uniform across species, decreasing the likelihood of immunogenicity, and it is normally present in human tissue, including the skin and synovial joint fluid. ${ }^{15-20}$

For injectable fillers, hyaluronic acid is modified through cross-linking in order to strengthen its mechanical properties and increase resistance to breakdown. Of the various products from different manufacturers, distinguishing characteristics include particle size, degree and method of crosslinkage, concentration of cross-linked/free hyaluronic acid, and resistance to deformation. The degree of modification is characterized by the formation of cross-linkage (bond between two strands) and pendant (bonding present at only one end). The longevity of product is influenced primarily by the concentration and degree of cross-linking. ${ }^{16,17,21}$

There are many Food and Drug Administration-approved hyaluronic acid fillers available with similar approved indications. The use of these fillers in the periocular area is generally considered "off label." ${ }^{20}$ Each of the specific fillers has their unique characteristics of elasticity and viscosity. Of the available fillers, Restylane (Galderma Laboratories) and Juvéderm Ultra (Allergan, Inc.) are well suited for injecting into the periorbital region. Belotero (Merz Aesthetics, Inc.) is a more recently introduced cohesive (monophasic) polydensified filler that may integrate more homogenously within dermal tissue. ${ }^{21}$

Both Restylane and Juvéderm have been reported to have good efficacy and safety for the treatment of the nasolabial fold and have shown better longevity versus cross-linked collagen. ${ }^{10,13,15,21-26}$ There have been high patient satisfaction and low morbidity with hyaluronic acid gel in the treatment of the lower eyelid periorbital hollows as well as for upper eyelid contouring. 10,15

\section{Injection Technique}

A meticulous history and physical examination focused on identifying the areas of volume deficiency is performed. An assessment for signs of edema and fluid retention should be performed. Evidence of skin changes such as sun damage, wrinkles, should be noted, as these will remain unchanged with filler and will likely require supplemental treatment. Informed consent is obtained.

The patient's skin may be anesthetized with ice, cold air, topical anesthetic, or focal vibration. While regional blocks to the infraorbital and supraorbital nerves can be administered, 

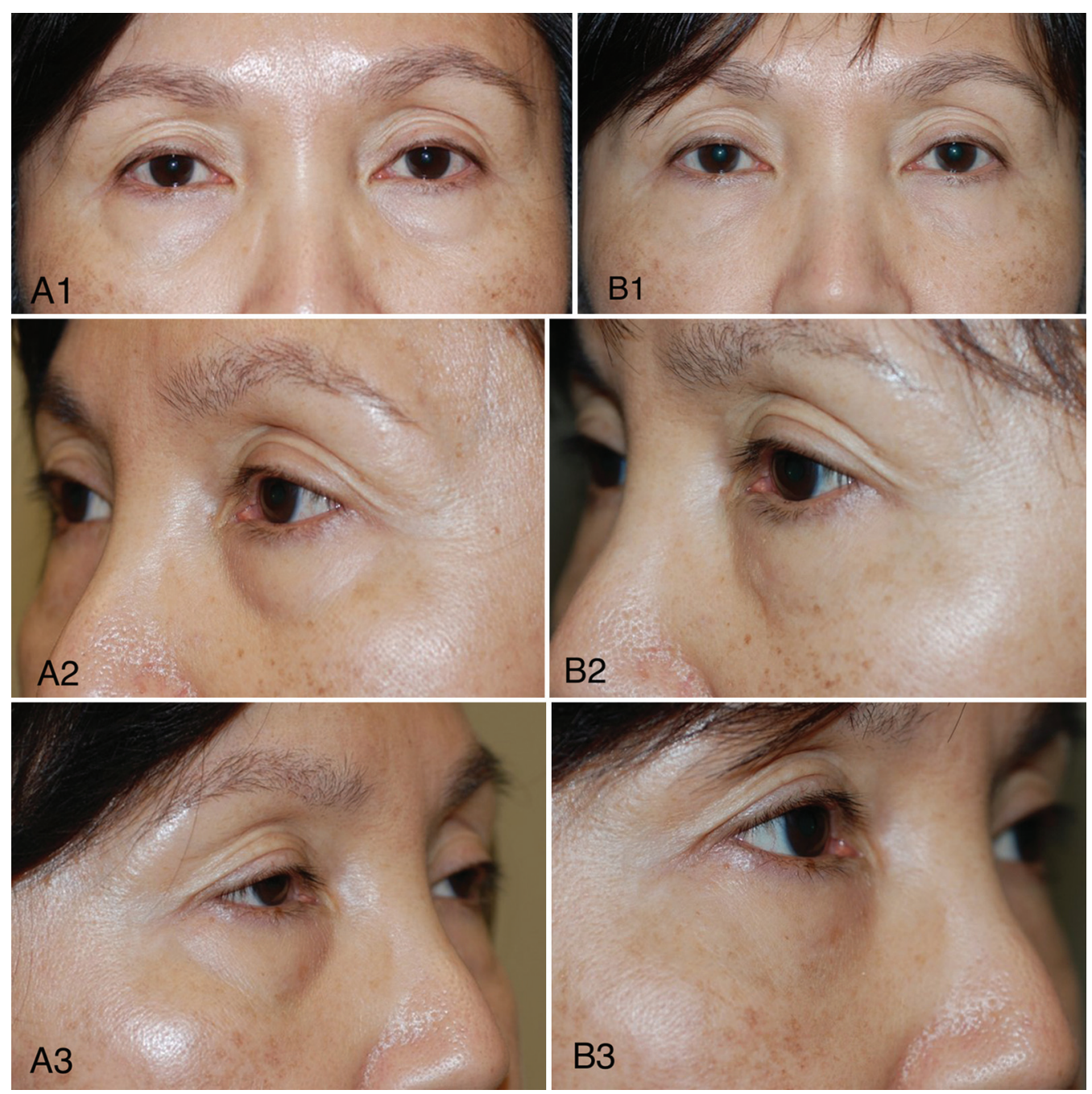

Fig. 2 Pretreatment (A) and posttreatment images (B) of a patient who was treated with hyaluronic acid gel and chemical peel to the bilateral lower eyelid area.

infiltrative local anesthetic can distort tissue, complicating injection of filler and should be avoided.

In the upper eyelid, while the patient is looking down, a 30-gauge needle is used to puncture the skin at the superolateral orbital rim. The needle is advanced in the suborbicularis plane to the inferior border of the superior orbital rim. Some authors suggest an initial puncture with a larger gauge needle, followed by insertion of a blunt cannula. A small aliquot of filler $(\sim 0.1 \mathrm{ml})$ is deposited in linear droplet fashion in the supraperiosteal plane. After the needle is withdrawn, the filler is gently, but firmly molded with digital to evenly distribute the filler. Additional filler can be delivered in a feathered, linear droplet fashion and the process repeated until the desired volume has been delivered to the planned area. One must avoid injury to the supraorbital neurovascular bundle. For patients with exposure of the lateral orbital rim, filler can be placed along the lateral orbital rim and sub-brow in a similar fashion ( $\sim .1$ to $0.5 \mathrm{ml})$.

In the lower eyelid, a 30-gauge needle is used to puncture the skin. The needle travels in the suborbicularis plane in the hollowed areas overlying the inferior orbital rim. Filler is delivered, using multiple passes to deposit the filler in a linear, feathered fashion ( $\sim 0.3$ to $0.5 \mathrm{ml})$. The needle is then withdrawn, and gentle, yet firm digital pressure is utilized to mold the product in the desired fashion.

Given the very thin skin of the upper and lower eyelids, contour and color irregularities may be more readily noticeable. To minimize lumps and irregularities, one must avoid depositing significant amounts of filler in one location, but rather, in a linear, feathered, thread-like pattern. The filler can also be molded with digital pressure. If bruising is noted, gentle focal pressure is applied to the area.

\section{Complications}

Hyaluronic acid fillers have low rates of side effects without significant recovery times. Common side effects include bruising, redness, pain during the injection, contour irregularities, and filler visibility/bluish hue (Tyndall effect). ${ }^{9-12} \mathrm{An}$ important and not uncommon complication is under- or over- 
filling. Inadequate filling may initially be masked by tissue edema or acute hemorrhage. Furthermore, hyaluronic acid will attract water and may be associated with more noticeable edema given the very thin skin of the eyelids. As such, the final filling effect may take several days to stabilize. If additional volume is required, an injection of additional filler can be administered. Mild overfilling can usually be managed with massage to flatten and/or disperse the hyaluronic acid. However, if massage is not producing the desired effect, hyaluronidase can be injected to dissolve the hyaluronic acid. ${ }^{26-30}$ In cases of persistent edema, minimal response to hyaluronidase is rare and may be related to protein contaminants in the filler. ${ }^{26}$

While rare, serious complications can occur, and prompt recognition is important in minimizing sequelae. Arterial occlusion becomes symptomatic immediately with blanching and pain, while venous occlusion may be delayed in presentation. Both should be treated with vigorous massage, warm compresses, and nitroglycerin paste. Vascular compromise tends to be more commonly reported in the glabellar area, presumably due to the presence of small caliber vessels and a lack of good collateral circulation. Lastly, while extremely rare, vision-threatening complications have been reported from embolization of filler material to the central retinal artery. ${ }^{26-33}$ Authors have suggested a linear, feathered deposition of material to minimize these risks, and others have suggested the use of blunt cannulas for injection.

Delayed complications occurring days to weeks postinjection include persistent nodularity, infection, and angioedema. Firm, gentle massage may be helpful for noninflammatory nodules, while inflammatory nodules can be caused by infectious etiologies and antibiotic coverage/incision drainage may be necessary. ${ }^{26-33}$

\section{Conclusion}

There has been an increased recognition for the role of volume deflation in the aging periorbital area, leading to the development of new rejuvenation strategies. Hyaluronic acid fillers, because of their efficacy, longevity, and safety profile, have largely replaced collagen fillers. An understanding of the changes in the upper and lower periocular area due to age coupled with the precise delivery of filler work together to smooth contours and rejuvenate the periorbital area. Careful patient selection and the tailored selection of complementary treatment modalities, such as neurotoxins, skin resurfacing procedures, and surgery, are equally important elements in achieving periorbital rejuvenation.

\section{References}

1 Liew S, Nguyen DQ. Nonsurgical volumetric upper periorbital rejuvenation: a plastic surgeon's perspective. Aesthetic Plast Surg 2011;35(3):319-325

2 Morley AM, Taban M, Malhotra R, Goldberg RA. Use of hyaluronic acid gel for upper eyelid filling and contouring. Ophthal Plast Reconstr Surg 2009;25(6):440-444

3 Kahn DM, Shaw RB Jr. Aging of the bony orbit: a three-dimensional computed tomographic study. Aesthet Surg J 2008;28(3):258-264
4 Pessa JE, Desvigne LD, Lambros VS, Nimerick J, Sugunan B, Zadoo VP. Changes in ocular globe-to-orbital rim position with age: implications for aesthetic blepharoplasty of the lower eyelids. Aesthetic Plast Surg 1999;23(5):337-342

5 Levine RA, Garza JR, Wang PT, Hurst CL, Dev VR. Adult facial growth: applications to aesthetic surgery. Aesthetic Plast Surg 2003;27(4):265-268

6 Mancini R, Khadavi NM, Goldberg RA. Nonsurgical management of upper eyelid margin asymmetry using hyaluronic acid gel filler. Ophthal Plast Reconstr Surg 2011;27(1):1-3

7 Goldberg RA. The three periorbital hollows: a paradigm for periorbital rejuvenation. Plast Reconstr Surg 2005;116(6): 1796-1804

8 Yousif NJ, Matloub M D And H, Summers AN. The midface sling: a new technique to rejuvenate the midface. Plast Reconstr Surg 2002;110(6):1541-1553, discussion 1554-1557

9 Finn JC, Cox S. Fillers in the periorbital complex. Facial Plast Surg Clin North Am 2007;15(1):123-132, viii

10 Goldberg RA, Fiaschetti D. Filling the periorbital hollows with hyaluronic acid gel: initial experience with 244 injections. Ophthal Plast Reconstr Surg 2006;22(5):335-341, discussion 341-343

11 André P. Evaluation of the safety of a non-animal stabilized hyaluronic acid (NASHA - Q-Medical, Sweden) in European countries: a retrospective study from 1997 to 2001.J Eur Acad Dermatol Venereol 2004;18(4):422-425

12 Friedman PM, Mafong EA, Kauvar AN, Geronemus RG. Safety data of injectable nonanimal stabilized hyaluronic acid gel for soft tissue augmentation. Dermatol Surg 2002;28(6):491-494

13 Baumann LS, Shamban AT, Lupo MP, et al; JUVEDERM vs. ZYPLAST Nasolabial Fold Study Group. Comparison of smooth-gel hyaluronic acid dermal fillers with cross-linked bovine collagen: a multicenter, double-masked, randomized, within-subject study. Dermatol Surg 2007;33(Suppl 2):S128-S135

14 Johl SS, Burgett RA. Dermal filler agents: a practical review. Curr Opin Ophthalmol 2006;17(5):471-479

15 Bogdan Allemann I, Baumann L. Hyaluronic acid gel (Juvéderm) preparations in the treatment of facial wrinkles and folds. Clin Interv Aging 2008;3(4):629-634

16 Falcone SJ, Berg RA. Crosslinked hyaluronic acid dermal fillers: a comparison of rheological properties. J Biomed Mater Res A 2008; 87(1):264-271

17 Kablik J, Monheit GD, Yu L, Chang G, Gershkovich J. Comparative physical properties of hyaluronic acid dermal fillers. Dermatol Surg 2009;35(Suppl 1):302-312

18 Tezel A, Fredrickson GH. The science of hyaluronic acid dermal fillers. J Cosmet Laser Ther 2008;10(1):35-42

19 Stocks D, Sundaram H, Michaels J, Durrani MJ, Wortzman MS, Nelson DB. Rheological evaluation of the physical properties of hyaluronic acid dermal fillers. J Drugs Dermatol 2011;10(9):974-980

20 Wrinkle fillers approved by the Center for Devices and Radiological Health. Available at: http://www.fda.gov/MedicalDevices/ProductsandMedicalProcedures/CosmeticDevices/WrinkleFillers/ ucm227749.htm. Accessed November 30, 2016

21 Tran CP, Carraux PR, Micheels PA, Kaya G, Salomon D. In vivo biointegration of three hyaluronic acid fillers in human skin: a histological study. Dermatology 2014;228(1):47-54

22 Lupo MP, Smith SR, Thomas JA, Murphy DK, Beddingfield FC III. Effectiveness of Juvéderm Ultra Plus dermal filler in the treatment of severe nasolabial folds. Plast Reconstr Surg 2008;121(1): 289-297

23 Pinsky MA, Thomas JA, Murphy DK, Walker PS; Juvéderm vs. Zyplast Nasolabial Fold Study Group. Juvéderm injectable gel: a multicenter, double-blind, randomized study of safety and effectiveness. Aesthet Surg J 2008;28(1):17-23

24 Levy PM, De Boulle K, Raspaldo H. A split-face comparison of a new hyaluronic acid facial filler containing pre-incorporated lidocaine versus a standard hyaluronic acid facial filler in the treatment of naso-labial folds. J Cosmet Laser Ther 2009;11(3):169-173 
25 Tung R, Ruiz de Luzuriaga AM, Park K, Sato M, Dubina M, Alam M. Brighter eyes: combined upper cheek and tear trough augmentation: a systematic approach utilizing two complementary hyaluronic acid fillers. J Drugs Dermatol 2012;11(9):1094-1097

26 Cox SE, Adigun CG. Complications of injectable fillers and neurotoxins. Dermatol Ther (Heidelb) 2011;24(6):524-536

27 Rzany B, Cartier H, Kestemont P, et al. Full-face rejuvenation using a range of hyaluronic acid fillers: efficacy, safety, and patient satisfaction over 6 months. Dermatol Surg 2012;38(7 Pt 2):1153-1161

28 Hirsch RJ, Stier M. Complications of soft tissue augmentation. J Drugs Dermatol 2008;7(9):841-845

29 Gladstone HB, Cohen JL. Adverse effects when injecting facial fillers. Semin Cutan Med Surg 2007;26(1):34-39
30 Glaich AS, Cohen JL, Goldberg LH. Injection necrosis of the glabella: protocol for prevention and treatment after use of dermal fillers. Dermatol Surg 2006;32(2):276-281

31 Schanz S, Schippert W, Ulmer A, Rassner G, Fierlbeck G. Arterial embolization caused by injection of hyaluronic acid (Restylane). $\mathrm{Br}$ J Dermatol 2002;146(5):928-929

32 Bachmann F, Erdmann R, Hartmann V, Wiest L, Rzany B. The spectrum of adverse reactions after treatment with injectable fillers in the glabellar region: results from the Injectable Filler Safety Study. Dermatol Surg 2009;35(Suppl 2):1629-1634

33 Leonhardt JM, Lawrence N, Narins RS. Angioedema acute hypersensitivity reaction to injectable hyaluronic acid. Dermatol Surg 2005;31(5):577-579 